\title{
Parâmetros técnicos para outorga de direito de uso da água para aquicultura no estado de Santa Catarina, Brasil
}

\author{
Technical parameters for water resources allocation for \\ aquaculture in the state of Santa Catarina, Brazil
}

Izabella Alves Cordeiro de Farias ${ }^{1}$ (D), Leonardo Schorcht Bracony Porto Ferreira ${ }^{2}$ (D), Rodrigo Nascimento e Silva ${ }^{1}$ (D), Celso Lopes de Albuquerque Junior ${ }^{3}$ (D), Katt Regina Lapa ${ }^{1}$ (D)

${ }^{1}$ Universidade Federal de Santa Catarina - UFSC, Florianópolis, SC, Brasil. E-mails: izafarias28@gmail.com, rodrigobio@hotmail.com, kr.lapa@gmail.com

2Secretaria Executiva do Meio Ambiente, Florianópolis, SC, Brasil. E-mail: leo.portoferreira@hotmail.com

${ }^{3}$ Conselho Regional de Engenharia e Agronomia de Santa Catarina, Tubarão, SC, Brasil. E-mail: celsohorti@gmail.com

Como citar: Farias, I. A. C., Ferreira, L. S. B. P., Silva, R. N., Albuquerque Junior, C. L., \& Lapa, K. R. (2021). Parâmetros técnicos para outorga de direito de uso da água para aquicultura no estado de Santa Catarina, Brasil. Revista de Gestão de Água da América Latina, 18, e9. https://doi.org/10.21168/rega.v18e9

\begin{abstract}
RESUMO: Este trabalho tem como objetivo estabelecer uma proposta de cálculo de demanda hídrica para as atividades aquícolas continental, designando parâmetros que fundamentem o processo de análise das outorgas de direito de uso dos recursos hídricos para aquicultura em Santa Catarina, Brasil. 0 estado ainda não possui os parâmetros técnicos definidos que contemple a atividade. Desta maneira, no processo de licenciamento, os produtores passíveis de outorga são dispensados. A demanda de água para abastecer a atividade dependerá da área de cultivo instalada, perdas por infiltração de acordo com o tipo de solo, perdas pela taxa de evaporação, volume precipitado e taxas de renovação do sistema. As espécies de maior interesse econômico na região são as tilápias (Oreochromis niloticus), espécies variadas de carpas em policultivo, camarão-branco (Litopenaeus vannamei) e as trutas (Oncorhynchus mykiss). Os sistemas de cultivo são majoritariamente desenvolvidos em viveiros escavados, sendo que o sistema semi-intensivo de produção é o mais usual, seguido pelo intensivo e extensivo, respectivamente. No sistema intensivo, a espécie demanda grandes taxas de renovação (100\% por hora), enquanto que o sistema semi-intensivo demanda baixas renovações (5\% ao dia). As principais dificuldades relativas às implementações da outorga no estado de Santa Catarina envolvem tanto questões técnicas, administrativas e de disponibilidade de recursos hídricos.
\end{abstract}

Palavras-chave: Alocação de Água; Gerenciamento de Recursos Hídricos; Outorga para Piscicultura.

ABSTRACT: This work aims to establish a proposal for the calculation of water demand for continental aquaculture activities, designating parameters that support the process of analysis of water allocation for aquaculture in Santa Catarina, Brazil. The state does not have the defined technical parameters that contemplate the activity, thus, in the licensing process, producers subject to an allocation are exempted. The demand for water to supply the activity will depend on the installed cultivation area, infiltration losses according to the type of soil, losses due to the evaporation rate, the precipitated volume and water exchanged rate. The species of greatest economic interest in the region are tilapia (Oreochromis niloticus), varied species of carp in polyculture, white shrimp (Litopenaeus vannamei) and trout (Oncorhynchus mykiss). Cultivation systems are mostly developed in earthen ponds, with the semi-intensive production system being the most common, followed by the intensive and extensive, respectively. In the intensive system, the species demands high renewal rates (100\% per hour), while the semi-intensive system demands low renewals ( $5 \%$ per day). The main difficulties related to the implementation of the water allocation in the state of Santa Catarina involve both technical, administrative and water resources availability issues.

Keywords: Allocation of Water; Management of Water Resources; Water Allocation for Fish-Farming.

\section{INTRODUÇÃO}

Água é o recurso mais importante em todos os aspectos da vida. Seu correto manejo conduz a excelentes resultados nas atividades humanas. Porém seu mau uso pode provocar degeneração do meio físico natural, bem como, afetar as relações humanas (Casarin \& Santos, 2018). A disponibilidade

Recebido: Março 30, 2021. Revisado: Julho 03, 2021. Aceito: Agosto 06, 2021. 
de água doce está mudando em todo o mundo, no qual a distribuição heterogênea dos recursos hídricos juntamente com a disponibilidade de água limpa é potencialmente um dos problemas mais importantes que a comunidade mundial terá de enfrentar nos próximos anos (Rodell et al., 2018).

Embora seja comum a percepção de que o Brasil é um país com água em abundância, para garantir uma equidade na distribuição desse bem comum, deve ser considerada a disposição populacional e as projeções de incremento das diversas demandas setoriais, incluindo as demandas decorrentes do crescimento da população, como fatores de pressão sobre o recurso hídrico disponível (Lopes et al., 2016). Antes de se planejar a utilização dos recursos naturais faz-se necessário o conhecimento prévio dos mesmos, ou seja, identificar suas características qualitativas e quantitativas (Montaño \& Souza, 2016).

Com essa necessidade de planejamento territorial dos recursos hídricos, a gestão das águas foi determinada em unidades denominadas bacias hidrográficas, nas quais todas as áreas urbanas, industriais, agrícolas ou de preservação fazem parte de alguma bacia (Porto \& Porto, 2008). A realização da gestão destas envolve vários aspectos sociais e políticos de bases de dados distintas (Peres \& Silva, 2013).

Para que as decisões dos planejamentos sejam mais efetivas e condizentes com a necessidade, é fundamental que a outorga do uso da água seja realizada pelos usuários. Segundo Conejo (1993), é na análise das outorgas onde são delimitados a quantidade de água retirada e a quantidade devolvida pelo efluente, estando sujeitas as restrições sazonais ou condições de escoamento. Para que a implantação do instrumento da outorga possa ser realizada de maneira efetiva, é necessário o conhecimento do comportamento nas bacias hidrográficas, especialmente a determinação das vazões de referência, a fim de fundamentar o processo decisório (Oliveira \& Fioreze, 2011). Os Estados da União são responsáveis pela outorga das águas subterrâneas, rios, lagos, reservatórios e açudes que tenham sua nascente e sua foz dentro de seu território (Agência Nacional de Águas, 2014).

A Lei Estadual 9.748, de 30 de novembro de 1994, Art. 29, descreve que qualquer empreendimento ou atividade que altere as condições quantitativas e/ou qualitativas das águas superficiais ou subterrâneas dependa de outorga, considerando o Plano estadual de Recursos Hídricos e os Planos de Bacia Hidrográfica. Os Planos Diretores das bacias determinam qual a vazão de uso insignificante de acordo com os aspectos de cada bacia hidrográfica. Conforme a Portaria SDS № 035 de 2006, Art. 7, não são objetos de outorga de direito de uso de recursos hídricos as vazões de captação máximas instantâneas inferiores a $1,0 \mathrm{~m}^{3} / \mathrm{h}$, quando não houver deliberação diferente do Conselho Estadual de Recursos Hídricos - CERH (Brasil, 2006).

Neste contexto a aquicultura é uma atividade econômica que, do ponto de vista dos recursos hídricos, é caracterizada como uso não-consuntivo da água, ou seja, a maior parte da água captada retorna à fonte de suprimento em algum momento, podendo existir modificações no padrão temporal de disponibilidade e qualidade (Agência Nacional de Águas, 2014).. Os cultivos aquícolas continentais, em geral, são praticados em tanques escavados com volume significativo de água, sendo assim passíveis de outorga para captação e adução de água até os tanques de cultivo, além de outorga para lançamento dos efluentes provenientes dos mesmos (Deus \& Latuf, 2019).

Para estabelecer as demandas hídricas devem ser levadas em conta as principais características do sistema de produção aquícola, como a área de espelho d'água, o volume de armazenamento e a taxa de renovação diária de água. Além disso, deve-se considerar também as perdas hídricas por infiltração e evaporação. 0 requerente deverá apresentar informações relativas ao empreendimento de acordo com o cultivo a ser praticado, como os estágios de produção, quais espécies animais produzidas na fazenda, quantidades, densidades e outras informações cabíveis, de modo que permitam ao analista a verificação do uso racional da água (Deus \& Latuf, 2019). Decisões tomadas a partir de informações de vazão pouco representativas podem comprometer a gestão e o planejamento de recursos hídricos (Brigolin et al., 2015).

Atualmente em Santa Catarina, os aquicultores continentais devem ser regularizados e cadastrados como usuários de água pelo Sistema de Informações de Recursos Hídricos do Estado de Santa Catarina (SIRHESC). No entanto, os critérios e os parâmetros técnicos das outorgas de direito de uso dos recursos hídricos não estão estabelecidos para as atividades aquícolas. Desta maneira, no licenciamento ambiental das propriedades, os aquicultores são dispensados do processo de outorga de direito de uso da água. Esta situação é uma problemática na gestão quanto para o incremento da atividade no estado, uma vez que é visto o progresso da aquicultura continental (Sistema de Informações e Recursos Hídricos do Estado de Santa Catarina, 2019; PeixeBR, 2020).

Diante deste cenário, o objetivo deste estudo é estabelecer um modelo de determinação dos parâmetros para avaliação da demanda hídrica e uso racional nas análises das outorgas de direito de uso dos recursos hídricos. Os cálculos foram realizados a partir da avaliação das peculiaridades dos 
principais sistemas e espécies de cultivo implantados em Santa Catarina e suas necessidades de captação hídrica, considerando os tipos de solo e peculiaridades meteorológicas, de modo geral.

\section{MATÉRIAL E MÉTODOS}

\section{Área de estudo}

0 presente trabalho foi realizado tomando como base o estado de Santa Catarina, localizado na região sul do Brasil, cuja coordenadas geográficas são $25^{\circ} 57^{\prime} 41^{\prime \prime}$ e $29^{\circ} 23^{\prime} 55^{\prime \prime}$ e $48^{\circ} 19^{\prime} 37^{\prime \prime} \mathrm{W}$ e $53^{\circ} 50^{\prime} 00^{\prime \prime} \mathrm{W}$.

O estado possui área total de aproximadamente $95.736 \mathrm{~km}^{2}$, que representa 1,12\% da superfície do território nacional (Santa Catarina, 2018). É dividido em 10 regiões hidrográficas e 27 áreas de bacia hidrográfica, como mostra a Figura 1.

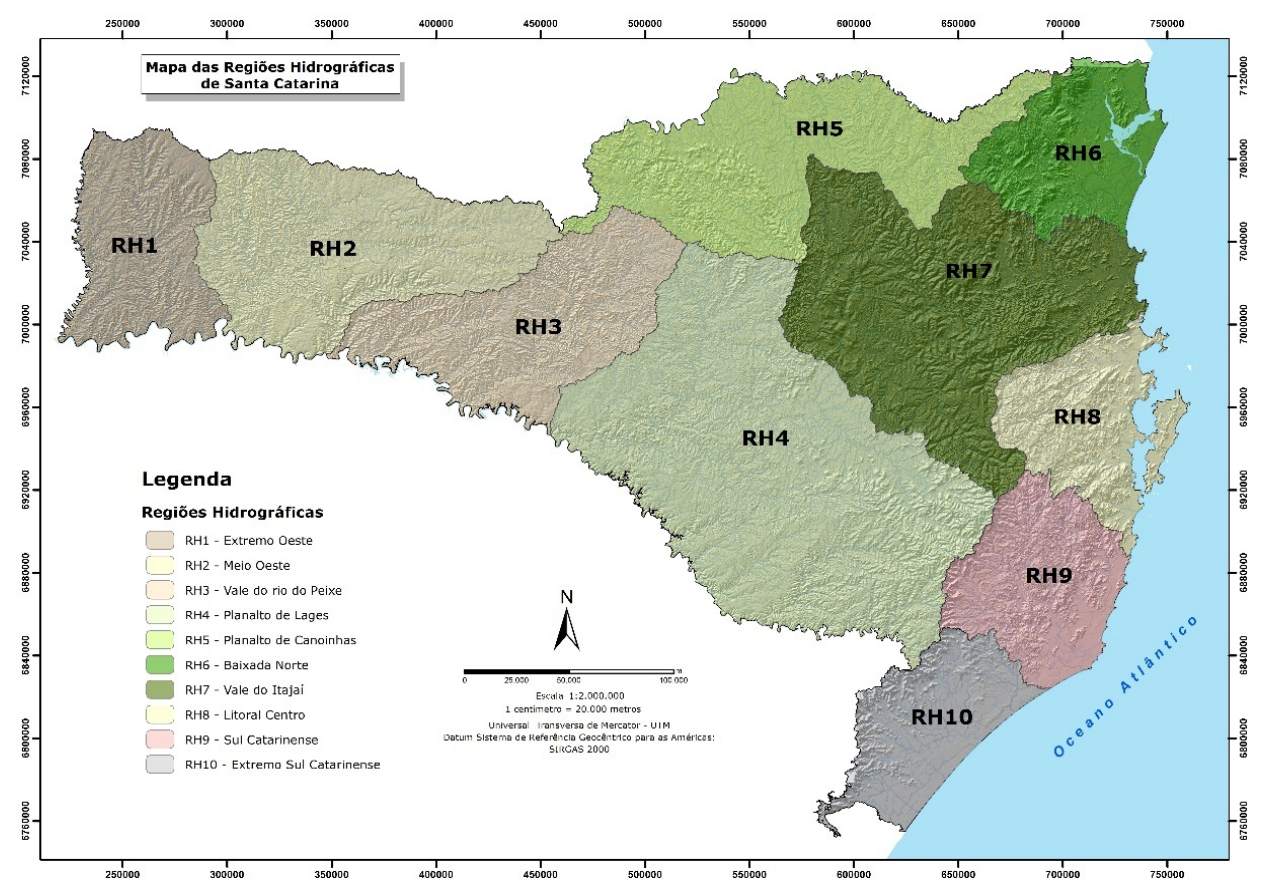

Figura 1 - mapa das regiões hidrográficas do estado de Santa Catarina.

A aquicultura em Santa Catarina é bastante expressiva no cenário brasileiro; no ano de 2019 o estado foi $3^{\circ}$ maior produtor de tilápia e o $2^{\circ}$ maior produtor de carpas e trutas, sendo o $4^{\circ}$ maior produtor de peixes de cultivo do país. Os dados da PeixeBR (2020) mostram a tendência de crescimento no setor para os anos futuros; no ano de 2019 a região Sul teve aumento de 15,51\% da produção em relação ao ano de 2018, foi a região do país com maior crescimento no período.

\section{Caracterização das espécies e sistema de cultivo}

Primeiramente foram caracterizadas as espécies aquícolas produzidas utilizando a base de dados do Centro de Desenvolvimento da Aquicultura e Pesca, da Empresa de Pesquisa Agropecuária e Extensão Rural de Santa Catarina (EPAGRI/CEDAP).

Conforme os dados do Centro de Desenvolvimento em Aquicultura e Pesca da Empresa de Pesquisa Agropecuária e Extensão Rural de Santa Catarina (Empresa de Pesquisa Agropecuária e Extensão Rural de Santa Catarina, 2019b), as espécies mais significativas para a piscicultura são as tilápias (Oreochromis niloticus) com 75,98\%, seguido pelo cultivo de diferentes espécies de carpas (Cyprinus carpio, Ctenopharyngodon idella, Hypophthalmichthys nobilis, H. molitrix) com 18,56\%, jundiá (Rhamdia quelen) com 1,45\%, truta (Oncorhynchus mykiss) 1,45\%. Na mesma base, foram identificados os principais sistemas de cultivo empregados, sendo majoritariamente produzidas em viveiros escavados em sistema semi-intensivo de criação. 
O Quadro 1 classifica as espécies mais produzidas e os sistemas de cultivo empregados pelos principais modelos de fazendas continentais.

Quadro 1 - Caracterização das principais espécies e sistemas de cultivos da aquicultura continental de Santa Catarina.

\begin{tabular}{c|c|c|c}
\hline \multicolumn{1}{c|}{ Espécie } & Sistema & Unidade de produção & Renovação de água \\
\hline Tilápia & Semi-intensivo & Viveiros escavados & Baixa \\
\hline Carpas & Semi-intensivo & Viveiros escavados & Baixa \\
\hline Camarão & Semi-intensivo & Viveiros escavados & Baixa \\
\hline Trutas & Intensivo & Raceway & Alta/constante \\
\hline
\end{tabular}

Fonte: Adaptado dos dados da EPAGRI/CEDAP (Empresa de Pesquisa Agropecuária e Extensão Rural de Santa Catarina, 2019b).

\section{Demanda hídrica}

As estimativas de demanda hídrica pelos sistemas de cultivos mais usuais do estado, se deu através das seguintes fórmulas adaptadas do estudo de Ituassú \& Spera, (2018):

1) Vench $=A \times p$

Em que:

-Vench: Volume de enchimento do viveiro (L)

- A: Área do viveiro $\left(\mathrm{m}^{2}\right)$

- $p$ : Profundidade $(\mathrm{m})$

As medidas utilizadas para este estudo foram 4 dimensões de viveiros escavados, sendo de: área $100 \mathrm{~m}^{2}$ com 1,0 m de profundidade, $1.000 \mathrm{~m}^{2} \mathrm{com} 1,2 \mathrm{~m}$ de profundidade, $3.000 \mathrm{~m}^{2}$ com $1,5 \mathrm{~m}$ de profundidade e $10.000 \mathrm{~m}^{2}$ com $1,0 \mathrm{~m}$ de profundidade.

2) Vefet $=$ Vench + Vrep

Em que:

- Vefet: Volume efetivo do viveiro (L)

- Vench: Volume de enchimento (L)

- Vrep: Volume reposto (L)

Para o sistema semi-intensivo foi considerado baixa renovação de água diária, sendo resposto diariamente $5 \%$ do volume do viveiro.

No sistema intensivo foi considerado a troca de água de $100 \%$ do volume do viveiro por hora, perfazendo a renovação diária $2.400 \%$ do volume do tanque.

3) $\operatorname{Vinf}=i \times A$

Em que:

- Vinf: Volume infiltrado: (L/t)

- $i$ : Taxa de infiltração (L/t)

- $A$ : Área do viveiro $\left(\mathrm{m}^{2}\right)$

Os solos mais usuais para aquicultura são os solos de textura média que tem taxa de infiltração de 12 a 20 milímetros por dia (mm/d), e solo siltoso a infiltração pode varia de 5 a $12 \mathrm{~mm} / \mathrm{d}$, conforme Ituassú \& Spera (2018). Assim sendo, para título de exemplo de cálculo, foi considerado a taxa de infiltração de $12 \mathrm{~mm} / \mathrm{d}$.

4) Volume evaporado $($ Ve $)=$ Area deviveiro $\times \Sigma$ Taxa de evaporação

5) Volume precipitado $(V p)=$ Área de viveiro $\times \Sigma$ precipitação

Os valores das taxas de evaporação e precipitação $(\mathrm{mm})$ foram obtidos através da média dos valores do Estado a partir do Formulário de Aquicultura para requerimento de outorga da Agência Nacional das Águas (ANA). 
A determinação da demanda hídrica total por ciclo de produção se dá pela equação (6) abaixo, que corresponde ao somatório das equações (1), (2), (3) e (4), com a subtração do valor da equação (5):

6) Demanda hídrica=Vreal + Vinf + Ve $-V p$

As demandas de água e as respectivas vazões foram estabelecidas para cada mês de cultivo, com início e enchimento dos viveiros no mês de setembro. Os meses subsequentes possuem o volume necessário para repor as perdas e renovar a água de acordo com a intensificação do sistema. Todos os cálculos foram realizados levando em consideração o tempo de cultivo médio praticado no estado, que pode ser de até 8 meses (1,5 ciclo/ano).

Os limites de consistência para as análises técnicas da outorga foram obtidos pelos limites mínimos individual outorgável, em que foi subtraído $20 \%$ da demanda hídrica estimada; e o limite máximo individual outorgável, em que foi somado $20 \%$ do valor da demanda hídrica estimada.

\section{RESULTADOS E DISCUSSÃo}

\section{Espécies cultivadas}

A aquicultura continental em Santa Catarina está baseada na produção de espécies exóticas, uma vez que, possuem o pacote tecnológico estabelecido e mais explorado que as espécies nativas. A tilápia (Oreochromis niloticus), de origem africana, é a principal espécie cultivada. Isso se justifica pelas vantagens zootécnicas, sendo uma espécie com crescimento rápido, ampla tolerância e alta capacidade de adaptação as variações ambientais. Porém, é uma das principais espécies escapadas que não são nativas do Brasil, podendo causar uma homogeneização biótica na região de escape (Rodrigues et al., 2012; Daga et al., 2015; Zaniboni-Filho et al., 2018).

0 potencial de severidade das espécies é uma característica importante no processo de licenciamento ambiental; ele é baseado na característica ecológica da espécie e no sistema de cultivo a ser utilizado (Paz et al., 2013). A classificação do risco ambiental dos empreendimentos aquícolas, segundo a resolução CONAMA nำ413, é feita de acordo com a origem (autóctone ou nativa, alóctone ou exótica), o hábito alimentar da espécie utilizada (não-carnívora, onívora, autotrófica) o sistema de cultivo empregado (extensivo, semi-intensivo ou intensivo) (Brasil, 2009).

A produção de espécies de clima tropical é a mais expressiva no estado pois possibilita uma diversidade maior das espécies cultiváveis. Por outro lado, a produção de espécies de águas frias é menos expressiva, concentrando-se na produção de trutas (Oncorhynchus mykiss), principalmente nas regiões de maiores altitudes (Giehl et al., 2020).

0 estado de Santa Catarina conta com 21 carcinicultores, com a produção total de 311,83 toneladas, sendo que a principal espécie cultivada é o Camarão-Branco-do-Pacífico (Litopenaeus vannamei) (Giehl et al., 2020). Por mais que esta seja uma espécie de camarão marinho, o L. vannamei é tipicamente eurialino suportando ampla variação de salinidade, característica esta, que favorece o cultivo em baixa salinidade (Fonseca et al., 2009).

Com a demanda crescente por pescado o estado passou a fornecer carpas para a região Sudeste do país, principalmente para o abastecimento de pesque-pague. A partir disto, o poli cultivo de peixes se fortaleceu como uns dos principais sistemas de criação de peixes de água doce em Santa Catarina. A utilização do sistema de poli cultivo é comumente empregado em pequenas propriedades rurais, pois diminui os custos de insumos. Nesta modalidade de cultivo, todas as espécies de carpas têm papel importante para o aproveitamento do alimento natural produzido no viveiro (Casaca, 2008; Ritter et al., 2014).

A produtividade aquícola sustentável é diretamente dependente da manutenção da qualidade do sistema aquático. Neste sentido, o produtor deve utilizar a água de forma racional sem deteriorar a sua qualidade e a sua disponibilidade, o que implica em adotar boas práticas de manejo que visam diminuir os riscos sanitários da produção e ampliam o aproveitamento dos recursos ambientais. A exemplo da truticultura, na qual a aplicação de altas taxas de densidade implica na utilização de altos volumes de renovação de água, pois o não aproveitamento total do alimento compromete a qualidade da mesma (Simões, 2016).

\section{Sistema de cultivo}

A implatanção dos cultivos em viveiros escavados é o modelo de cultivo mais difundido pelo país. Segundo Andrade (2020), o estado de Santa Catarina representa 30,48\% da aquicultura brasileira neste 
sistema, tendo o mais usual o semi-intesivo, seguido pelo intensivo e extensivo, respectivamente. A atividade é desenvolvida em pequenas propriedades rurais, com média de 2 hectares de lâmina d'água por propriedade e mão de obra familiar (Empresa de Pesquisa Agropecuária e Extensão Rural de Santa Catarina, 2019a). A quantidade necessária de água para aquicultura depende de vários fatores, como: clima, solo, sistema de cultivo adotado, densidade, práticas de manejo de acordo com o sistema de cultivo adotado (intensivo, semiintensivo ou extensivo) e a quantidade de renovação de água (Casaca, 2008).

A definição dos sistemas de produção serve como indicador do desenvolvimento tecnológico da atividade, quanto mais intensificada a produção, maior tecnologia empregada. Seu oposto é o sistema de produção extensivo, que se caracteriza por ter baixíssimas densidades de cultivo, grande ocupação de terra, menor uso de insumos e mão de obra pouco qualificada, configurando um sistema por vezes mais rústico (Andrade, 2020).

De acordo com Gutiérrez-Estrada et al. (2012), o sistema de cultivo impacta sobre a tecnologia e a demanda hídrica da produção. Nos tanques de alto fluxo de água em sistema intensivo, a qualidade da água nos tanques de cultivo é mantida pela contínua renovação. Isto é necessário para que haja retirada dos resíduos sólidos, principalmente as excretas dos animais aquáticos e restos de alimentos, tal qual as substâncias dissolvidas na água, como amônia, nitrito e gás carbônico. Consequentemente, o manejo da água nesse tipo de sistema depende, principalmente, da eficiência na remoção dos resíduos, comumente empregado a uma taxa de renovação de $100 \%$ do volume do viveiro por hora. A intensificação do sistema de cultivo eleva os custos, porém aumenta a sua produtividade quando projetada e executada de maneira efetiva. Um exemplo de modelo de produção intensiva no estado, é a utilização de tanque Raceway: o princípio deste modelo é a alta troca de água dos tanques, o fluxo de água é permanente e a renovação de água é realizada várias vezes durante o dia (Tabata \& Silva Filho, 2012).

O sistema semi-intensivo utiliza menores taxas de densidades e tecnologia, a produção de compostos dissolvidos e resíduos sólidos acaba por ser menor quando comparada ao modo intensivo, no que diz respeito qualidade de água. Nestes casos, a maior parte da reposição do volume de água é para repor o volume perdido por evaporação e infiltração. A reposição de água geralmente neste sistema, comumente não excede $5 \%$ do volume do tanque por dia. A renovação desnecessária de água, além de aumentar os custos, remove nutrientes e material orgânico particulado que auxilia a manutenção do plâncton na água, e ainda, pode prejudicar os efeitos da preparação do solo que antecede o cultivo (Kubitza, 2009).

\section{Volume dos viveiros}

A água necessária para o enchimento de uma unidade de produção depende da capacidade de acumulação deste. 0 dimensionamento é realizado com base em sua área e profundidade média (Oliveira, 2005). Para estabelecer o volume efetivo dos viveiros é necessário contabilizar qual taxa de renovação de água durante o ciclo de cultivo. Este valor deve ser adicionado para estabelecer o efetivo volume de água necessário do abastecimento da produção (Walber, 2007).

Na produção com sistema semi-intensivo a taxa de renovação diária é consideravelmente baixa, podendo ser 5 a $20 \%$ do volume do tanque, dependendo da densidade de indivíduos utilizado e do uso de aeradores (Avnimelech et al, 2008). A Tabela 1, dimensiona o volume dos viveiros considerando uma renovação diária de 5\% em diferentes dimensões, levando em consideração 8 meses (243 dias) de ciclo de cultivo.

Tabela 1 - Volume de água dos viveiros de diferentes dimensões em sistema semi-intensivo.

\begin{tabular}{cc|c|c|c|c}
\hline $\begin{array}{c}\text { Dimensões } \\
(\mathbf{m})\end{array}$ & $\begin{array}{c}\text { Área } \\
\left(\mathbf{m}^{\mathbf{2}} \mathbf{)}\right.\end{array}$ & $\begin{array}{c}\text { Profundidade } \\
\text { média } \\
\mathbf{( m )}\end{array}$ & $\begin{array}{c}\text { Volume } \\
\text { enchimento } \\
\text { (litros) }\end{array}$ & $\begin{array}{c}\text { Renovação } \\
\text { diária } \\
\mathbf{( \% )}\end{array}$ & $\begin{array}{c}\text { Volume efetivo } \\
\text { (litros) }\end{array}$ \\
\hline $10 \times 10$ & 100 & 1,0 & 100.000 & 5,0 & 1.315 .000 \\
\hline $50 \times 20$ & 1.000 & 1,2 & 1.200 .000 & 5,0 & 1.578 .000 \\
\hline $100 \times 30$ & 3.000 & 1,5 & 4.500 .000 & 5,0 & 59.175 .000 \\
\hline $1000 \times 10$ & 10.000 & 1,0 & 10.000 .000 & 5,0 & 131.500 .000 \\
\hline
\end{tabular}

Os sistemas de cultivos intensivos requerem maior investimento e tem alto custo de produção, tanto na construção dos viveiros quanto na oferta de ração de boa qualidade, uma vez que a disponibilidade de alimento natural é nula (Tabata \& Silva Filho, 2012). Logo, esses 
sistemas são mais recomendados para as espécies de maior valor econômico, que é o caso das trutas no estado.

Para se criar truta é fundamental a escolha adequada do local em que as condições ambientais sejam favoráveis ao bom desempenho da espécie: águas frias em abundância, limpas e com alto teor de oxigênio dissolvido. 0 fluxo de água deste sistema deve ser constante, de forma a permitir uma renovação completa do volume de água a cada hora (Tabata \& Silva Filho, 2012).

A Tabela 2, dimensiona o volume efetivo dos viveiros em sistema intensivo de produção.

Tabela 2 - Volume de água dos viveiros de diferentes dimensões em sistema intensivo.

\begin{tabular}{cc|c|c|c|c}
\hline $\begin{array}{c}\text { Dimensões } \\
(\mathbf{m})\end{array}$ & $\begin{array}{c}\text { Área } \\
\left(\mathbf{m}^{\mathbf{2}} \mathbf{n}\right.\end{array}$ & $\begin{array}{c}\text { Profundidade } \\
\text { média } \\
\mathbf{( m )}\end{array}$ & $\begin{array}{c}\text { Volume } \\
\text { enchimento } \\
\text { (litros) }\end{array}$ & $\begin{array}{c}\text { Renovação } \\
\text { diária } \\
(\mathbf{\%})\end{array}$ & $\begin{array}{c}\text { Volume efetivo } \\
\text { (litros) }\end{array}$ \\
\hline $10 \times 10$ & 100 & 1,0 & 100.000 & 2.400 & 58.420 .000 \\
\hline $50 \times 20$ & 1.000 & 1,2 & 1.200 .000 & 2.400 & 699.960 .000 \\
\hline $100 \times 30$ & 3.000 & 1,5 & 4.500 .000 & 2.400 & 26.248 .500 .000 \\
\hline $1000 \times 10$ & 10.000 & 1,0 & 10.000 .000 & 2.400 & 58.330 .000 .000 \\
\hline
\end{tabular}

No processo de outorga deve ser informado o número de vezes por ano em que os viveiros são esvaziados. Essa informação é necessária para se calcular o volume de reenchimento, ou seja, a quantidade de água usada todo ano para repor a água dos viveiros após estes terem sido esvaziados (Agência Nacional de Águas, 2013).

A despesca é o nome dado ao procedimento de retirada dos peixes de uma unidade de cultivo quando eles atingem o tamanho comercial desejado, podendo esta ser parcial ou total. Na parcial, apenas uma parte dos animais estocados são retirados com apetrechos específicos que não precisam do esvaziamento do viveiro. Isto normalmente ocorre quando somente alguns peixes atingiram o peso comercial. Por outro lado, na despesca total se retira todos os peixes do viveiro, necessitando do esvaziamento de alguma parte do volume de água para facilitar o manejo (Dotta \& Piazza, 2018). Desta maneira, no dimensionamento da demanda hídrica é necessário que o produtor informe o procedimento adotado para a despesca a fim de contabilizar os volumes corretos de reposição de água (Ituassú \& Spera, 2018).

\section{Perdas por infiltração}

0 processo de infiltração é relativo à porosidade, densidade, textura e grau de agregação do solo, bem como, dependerá da estrutura e região das unidades de cultivo no terreno; o termo "taxa de infiltração" é referente à quantidade de água que atravessa a unidade de área da superfície do solo por unidade de tempo (Panachuki et al., 2011).

Conhecer o solo em que se instalam os cultivos de aquicultura é fundamental tanto para o desempenho zootécnico da produção como para estabelecer a demanda de água necessária ao longo de um ciclo de cultivo. De acordo com Ituassú \& Spera (2018), para estabelecer o volume de água perdido é necessário saber qual taxa de infiltração, ou seja, a velocidade com que a água se infiltra. Essa taxa varia conforme o tipo de solo do local, uma vez que a granulometria exerce influência expressiva no processo hidráulico.

Segundo o estudo de Rocha (2020), superfícies consideradas arenosas (com mais de 90\% de areia), são inadequadas para a aquicultura, devido principalmente à baixa capacidade de interação física e química das partículas e à alta taxa de infiltração, assim como argilosas. Isto também ocorre com os solos predominantemente argilosos (com mais de $40 \%$ de argila) também são consideradas impróprias, pois são difíceis de se trabalhar durante a construção e manejo. Desta forma, os solos que apresentam teores de argila entre 5 e $10 \%$ e quantidades balanceadas de areia e silte são os mais adequados para a construção e manejo dos viveiros aquícolas (Poli, 2003).

A estimativa do volume de água infiltrada é realizada através da área dos viveiros em função da taxa de infiltração (i), as Tabelas 3 e 4 demonstram o volume de água por área de cultivo, de acordo com os solos mais adequados para aquicultura, sendo o solo de textura fina (siltoso) e textura média. 
Tabela 3 - Volume de água infiltrada (L/s) por área de cultivo em solo de textura média.

\begin{tabular}{c|c|c|c|c}
\hline $\begin{array}{c}\text { Área (m } \\
\text { i (m/d) }\end{array}$ & $\mathbf{1 0 0}$ & $\mathbf{1 . 0 0 0}$ & $\mathbf{3 . 0 0 0}$ & $\mathbf{1 0 . 0 0 0}$ \\
\hline 0,012 & 0,014 & 0,14 & 0,43 & 1,42 \\
\hline 0,013 & 0,015 & 0,15 & 0,46 & 1,54 \\
\hline 0,014 & 0,017 & 0,17 & 0,50 & 1,65 \\
\hline 0,015 & 0,018 & 0,18 & 0,53 & 1,77 \\
\hline 0,016 & 0,019 & 0,19 & 0,57 & 1,89 \\
\hline 0,017 & 0,020 & 0,20 & 0,60 & 2,01 \\
\hline 0,018 & 0,021 & 0,21 & 0,64 & 2,13 \\
\hline 0,019 & 0,022 & 0,22 & 0,67 & 2,25 \\
\hline 0,020 & 0,024 & 0,24 & 0,71 & 2,36 \\
\hline
\end{tabular}

i: Taxa de infiltração

Tabela 4 - Volume de água infiltrada (L/s) por área de cultivo em solo siltoso.

\begin{tabular}{c|c|c|c|c}
\hline $\begin{array}{c}\text { Área }\left(\mathbf{m}^{\mathbf{2}} \mathbf{)}\right. \\
\mathbf{i}(\mathbf{m} / \mathbf{d})\end{array}$ & $\mathbf{1 0 0}$ & $\mathbf{1 . 0 0 0}$ & $\mathbf{3 . 0 0 0}$ & $\mathbf{1 0 . 0 0 0}$ \\
\hline 0,005 & 0,006 & 0,059 & 0,18 & 0,59 \\
\hline 0,006 & 0,007 & 0,071 & 0,21 & 0,71 \\
\hline 0,007 & 0,008 & 0,083 & 0,25 & 0,83 \\
\hline 0,008 & 0,009 & 0,095 & 0,28 & 0,95 \\
\hline 0,009 & 0,011 & 0,106 & 0,32 & 1,06 \\
\hline 0,010 & 0,012 & 0,118 & 0,35 & 1,18 \\
\hline 0,011 & 0,013 & 0,130 & 0,39 & 1,30 \\
\hline 0,012 & 0,014 & 0,142 & 0,43 & 1,41 \\
\hline
\end{tabular}

i: Taxa de infiltração

Após a construção de viveiros, nos primeiros anos, há maior perda de água. Com o passar do tempo, os poros são vedados pela matéria orgânica produzida no viveiro, a taxa de infiltração diminui e se torna constante (Ituassú \& Spera, 2018). Nos casos de tanques de alvenaria ou viveiros revestidos, a perda de água pela infiltração é insignificante, uma vez que estes não estão em contato diretamente com o terreno, a infiltração não possui influência sobre estes (Silva, 1988).

As principais classes de solo do estado são os tipos de Latossolo, Podzólico, Terra Bruna, Cambissolo e Litólico (Bertol \& Almeida, 2000). Caso haja preferência por um maior detalhamento de infiltração, amostras de solo do local podem ser enviadas a um laboratório especializado, que determinará essas perdas em condições controladas (Ituassú \& Spera, 2018).

\section{Perdas por evaporação, precipitação e aspectos meteorológicos}

A evaporação da água dos viveiros varia de acordo com a localidade e estações do ano. Ela é acentuada pelas altas temperaturas, pela baixa umidade do ar e pela ação contínua dos ventos (Ono et al., 2002).

A Agência Nacional das Águas (ANA) disponibiliza no Formulário de Requerimento para Outorga da Aquicultura os dados de evaporação e precipitação média para cada localidade do país. A Tabela 5 abaixo, demonstra a quantidade de água obtidas pelas chuvas em cada área de cultivo, de acordo com os meses de cultivo.

Tabela 5 - Volume de água (L) de precipitação (Vp) por mês de cultivo.

\begin{tabular}{c|c|c|c|c}
\hline $\begin{array}{c}\text { Área }\left(\mathbf{m}^{2}\right) \\
\text { Mês }\end{array}$ & $\mathbf{1 0 0}$ & $\mathbf{1 . 0 0 0}$ & $\mathbf{3 . 0 0 0}$ & $\mathbf{1 0 . 0 0 0}$ \\
\hline 1 (Setembro) & 3,09 & 30,95 & 92,84 & 309,46 \\
\hline 2 (Outubro) & 5,32 & 53,25 & 159,74 & 532,46 \\
\hline 3 (Novembro) & 6,34 & 63,43 & 190,28 & 634,25 \\
\hline 4 (Dezembro) & 8,18 & 81,79 & 245,37 & 817,89 \\
\hline 5 (Janeiro) & 9,10 & 90,97 & 272,92 & 909,73 \\
\hline 6 (Fevereiro) & 8,61 & 86,14 & 258,41 & 861,38 \\
\hline 7 (Março) & 8,75 & 87,51 & 262,54 & 875,14 \\
\hline 8 (Abril) & 6,45 & 64,48 & 193,44 & 644,79 \\
\hline
\end{tabular}


Em Santa Catarina, segundo o trabalho de Gotado et al. (2018), o comportamento anual da precipitação é bianual, alternando entre períodos secos e úmido, com os maiores índices pluviométricos no verão e primavera. Conforme Gonçalves (2017), o estado de Santa Catarina é afetado por uma diversidade de eventos, que podem estar relacionados a severas estiagens como a grandes inundações e enxurradas.

Por sua vez, o volume de reposição é a quantidade de água necessária para repor as perdas por evaporação e infiltração, descontando-se os ganhos de água advindos das chuvas. Existem empreendimentos em que não há renovação de água, mas apenas reposição. Nesses casos, a demanda anual de água dependerá principalmente do volume de reposição (Agência Nacional de Águas, 2014). A Tabela 6, demonstra os valores de água mensal evaporado ao longo do ciclo de cultivo.

Tabela 6 - Volume de água (L) evaporado (Ve) por mês de cultivo.

\begin{tabular}{c|c|c|c|c}
\hline $\begin{array}{c}\text { Área }\left(\mathbf{m}^{2}\right) \\
\text { Mês }\end{array}$ & $\mathbf{1 0 0}$ & $\mathbf{1 . 0 0 0}$ & $\mathbf{3 . 0 0 0}$ & $\mathbf{1 0 . 0 0 0}$ \\
\hline 1 (Setembro) & 13,16 & 131,59 & 394,78 & $1.315,92$ \\
\hline 2 (Outubro) & 15,23 & 152,29 & 456,87 & $1.522,89$ \\
\hline 3 (Novembro) & 15,61 & 156,06 & 468,19 & $1.560,65$ \\
\hline 4 (Dezembro) & 16,17 & 161,74 & 485,23 & $1.617,42$ \\
\hline 5 (Janeiro) & 16,49 & 164,86 & 494,59 & $1.648,62$ \\
\hline 6 (Fevereiro) & 14,11 & 141,07 & 423,21 & $1.410,70$ \\
\hline 7 (Março) & 14,13 & 141,27 & 423,82 & $1.412,73$ \\
\hline 8 (Abril) & 11,83 & 118,28 & 354,83 & $1.182,76$ \\
\hline
\end{tabular}

Para determinar a real demanda hídrica, é preciso descontar o volume de escoamento superficial provenientes da precipitação, pois estes colaboram com o volume de água. A Tabela 7 ilustra os valores da diferença do ganho das chuvas com os valores das perdas por evaporação.

Tabela 7 - Diferença do volume de água evaporado (Ve) e volume (litros) precipitado (Vp).

\begin{tabular}{c|c|c|c|c}
\hline $\begin{array}{c}\text { Área }\left(\mathbf{m}^{2} \text { ) }\right. \\
\text { Mês }\end{array}$ & $\mathbf{1 0 0}$ & $\mathbf{1 . 0 0 0}$ & $\mathbf{3 . 0 0 0}$ & $\mathbf{1 0 . 0 0 0}$ \\
\hline 1 (Setembro) & 10,06 & 100,65 & 301,94 & $1.006,46$ \\
\hline 2 (Outubro) & 9,90 & 99,04 & 297,13 & 990,43 \\
\hline 3 (Novembro) & 9,26 & 92,64 & 277,92 & 926,39 \\
\hline 4 (Dezembro) & 8,00 & 79,95 & 239,86 & 799,53 \\
\hline 5 (Janeiro) & 7,39 & 73,89 & 221,67 & 738,89 \\
\hline 6 (Fevereiro) & 5,49 & 54,93 & 164,80 & 549,32 \\
\hline 7 (Março) & 5,38 & 53,76 & 161,28 & 537,59 \\
\hline 8 (Abril) & 5,38 & 53,80 & 161,39 & 537,98 \\
\hline
\end{tabular}

Os viveiros de aquicultura são formas de acumulação de água das bacias hidrográficas, contribuindo para regularização das vazões dos rios. De acordo com estudo de Queiroz; Silveira (2006), é recomendado projetar os viveiros nos vales e construir viveiros adicionais para aumentar o armazenamento de água nas bacias hidrográficas. Para Casaca (2020), não se deve construir em locais sujeitos a inundações, evitando assim a possibilidade de rompimento dos aterros e escape dos peixes.

\section{Estimativa da demanda hídrica}

A demanda por água pode ser influenciada por vários fatores, como o próprio cultivo em si, fatores relacionados à construção dos viveiros, tipos de solo e as espécies cultivadas, e, a aspectos hidromecânicos. Para Ituassú; Spera (2018), um projeto imperito para aquicultura tem a tendência de considerar que a demanda hídrica necessária para abastecimento ao longo do ciclo do cultivo é apenas para encher o volume dos viveiros. Se assim fosse, a demanda real seria subestimada, uma vez que grande parte da água é usada para repor as perdas por infiltração e evaporação, além da reposição por renovação. Silva (1988), já mencionava que na aquicultura convencional a demanda hídrica é a 
quantidade de água necessária para o enchimento inicial dos tanques de cultivo e a renovação continua, mais a quantidade de água para compensar as perdas por evaporação e infiltração (no caso de viveiros de terra).

A Tabela 8 apresenta a quantidade de água necessária para um ciclo de cultivo, considerando que o enchimento aconteça no mês de setembro. Os meses seguintes correspondem aos valores para repor as perdas nas unidades de cultivo e a taxa de renovação diária (5\%, usual do sistema semi-intensivo). A Tabela 9, do mesmo modo, caracteriza os valores de demanda hídrica para o sistema intensivo de produção, com $100 \%$ da renovação por hora.

Tabela 8 - Demanda hídrica (L) nos meses de cultivo em sistema semi-intensivo.

\begin{tabular}{c|c|c|c|c}
\hline $\begin{array}{c}\text { Área }\left(\mathbf{m}^{2}\right) \\
\text { Mês }\end{array}$ & $\mathbf{1 0 0}$ & $\mathbf{1 . 0 0 0}$ & $\mathbf{3 . 0 0 0}$ & $\mathbf{1 0 . 0 0 0}$ \\
\hline 1 (Setembro) & 235.000 & 2.820 .000 & 10.575 .000 & 23.500 .000 \\
\hline 2 (Outubro) & 155.000 & 1.860 .000 & 6.975 .000 & 15.500 .000 \\
\hline 3 (Novembro) & 150.000 & 1.800 .000 & 6.750 .000 & 15.000 .000 \\
\hline 4 (Dezembro) & 155.000 & 1.860 .000 & 6.975 .000 & 15.500 .000 \\
\hline 5 (Janeiro) & 155.010 & 1.860 .100 & 6.975 .301 & 15.501 .006 \\
\hline 6 (Fevereiro) & 140.009 & 1.680 .099 & 6.300 .297 & 14.000 .990 \\
\hline 7 (Março) & 155.009 & 1.860 .092 & 6.975 .277 & 15.500 .926 \\
\hline 8 (Abril) & 150.008 & 1.800 .079 & 6.750 .239 & 15.000 .799 \\
\hline Total & 1.295 .037 & 15.540 .372 & 58.276 .116 & 129.503 .722 \\
\hline
\end{tabular}

Tabela 9 - Demanda hídrica (L) nos meses de cultivo em sistema intensivo.

\begin{tabular}{c|c|c|c|c}
\hline $\begin{array}{c}\text { Área }\left(\mathbf{m}^{2}\right) \\
\text { Mês }\end{array}$ & $\mathbf{1 0 0}$ & $\mathbf{1 . 0 0 0}$ & $\mathbf{3 . 0 0 0}$ & $\mathbf{1 0 . 0 0 0}$ \\
\hline 1 (Setembro) & 6.580 .000 & 78.960 .000 & 2.920 .500 .000 & 6.490 .000 .000 \\
\hline 2 (Outubro) & 7.440 .000 & 89.280 .000 & 3.348 .000 .000 & 7.440 .000 .000 \\
\hline 3 (Novembro) & 7.200 .000 & 86.400 .000 & 3.240 .000 .000 & 7.200 .000 .000 \\
\hline 4 (Dezembro) & 7.440 .000 & 89.280 .000 & 3.348 .000 .000 & 7.440 .000 .000 \\
\hline 5 (Janeiro) & 7.440 .000 & 89.280 .000 & 3.348 .000 .000 & 7.440 .000 .000 \\
\hline 6 (Fevereiro) & 6.720 .000 & 80.640 .000 & 3.024 .000 .000 & 6.720 .000 .000 \\
\hline 7 (Março) & 7.440 .000 & 89.280 .000 & 3.348 .000 .000 & 7.440 .000 .000 \\
\hline 8 (Abril) & 7.200 .000 & 86.400 .000 & 3.240 .000 .000 & 7.200 .000 .000 \\
\hline Total & 57.460 .000 & 689.520 .000 & 25.816 .500 .000 & 57.370 .000 .000 \\
\hline
\end{tabular}

A quantidade de água que se utiliza durante o ciclo é chamada demanda sazonal, podendo variar com as condições climáticas da região onde o cultivo está instalado (Ramos, 2016).

A agricultura através da irrigação é a atividade que mais consome água em nível mundial. 0 arroz irrigado no sul do Brasil consome uma quantidade considerável quando comparada com os outros usos da água (Lorensi et al., 2010). Desta maneira, para não sobrecarregar a disponibilidade hídrica de uma bacia hidrográfica, é necessário reconhecer os períodos com maior disponibilidade de água e os períodos de escassez, considerando todas as atividades previstas pelo Plano Diretor das Bacias Hidrográficas.

Em Santa Catarina, os períodos favoráveis de semeadura do arroz são de agosto até janeiro (Steinmetz \& Braga, 2001). Deste modo, é aconselhado que os períodos de início das safras para aquicultura sejam entre os meses de setembro e outubro, para que a disponibilidade hídrica das bacias supra a demanda de água para o enchimento dos viveiros, sem competir com outras atividades por recursos hídricos, uma vez que após o enchimento dos viveiros a demanda de água é consideravelmente menor, usada para repor as perdas no caso do sistema semiintensivo.

Foram considerados que um ciclo de cultivo tem aproximadamente 243 dias, sendo os 3 primeiros dias para enchimento da lâmina de água. 0 "mês 1" considerou o início de um cultivo com um período de enchimento da área em 3 dias (72 h), somada as perdas e renovações para os restantes 27 dias de cultivo. 
A partir do "mês 2" considera-se as perdas de água e renovações de acordo com o sistema de cultivo utilizado até o "mês 8", em que ocorre a finalização da produção, com a despesca e preparo do solo para a próxima safra, considerando o número de dias de cada mês.

Levando em consideração o modelo de Silva (1988) para a vazão de enchimento de viveiros, a Tabela 10 demonstra as vazões em sistema semi-intensivo para cada mês de produção.

Tabela 10 - Vazão requerida (L/s) nos meses de cultivo em sistema semi-intensivo.

\begin{tabular}{c|c|c|c|c}
\hline $\begin{array}{c}\text { Área }\left(\mathbf{m}^{2} \text { ) }\right. \\
\text { Mês }\end{array}$ & $\mathbf{1 0 0}$ & $\mathbf{1 . 0 0 0}$ & $\mathbf{3 . 0 0 0}$ & $\mathbf{1 0 . 0 0 0}$ \\
\hline 1 (Setembro) & 0,115 & 1,349 & 20,397 & 45,793 \\
\hline 2 (Outubro) & 0,072 & 0,834 & 3,034 & 7,207 \\
\hline 3 (Novembro) & 0,072 & 0,834 & 3,034 & 7,207 \\
\hline 4 (Dezembro) & 0,072 & 0,834 & 3,034 & 7,207 \\
\hline 5 (Janeiro) & 0,072 & 0,834 & 3,034 & 7,207 \\
\hline 6 (Fevereiro) & 0,067 & 0,779 & 2,832 & 6,727 \\
\hline 7 (Março) & 0,072 & 0,834 & 3,034 & 7,207 \\
\hline 8 (Abril) & 0,072 & 0,834 & 3,034 & 7,207
\end{tabular}

Do mesmo modo, a Tabela 11 demonstra as vazões diárias para cada mês de cultivo em sistema intensivo de produção, com início em setembro e enchimento dos viveiros nos 3 primeiros dias.

Tabela 11 - Vazão requerida (L/s) nos meses de cultivo em sistema intensivo.

\begin{tabular}{c|c|c|c|c}
\hline $\begin{array}{c}\text { Área }\left(\mathbf{m}^{2}\right) \\
\text { Mês }\end{array}$ & $\mathbf{1 0 0}$ & $\mathbf{1 . 0 0 0}$ & $\mathbf{3 . 0 0 0}$ & $\mathbf{1 0 . 0 0 0}$ \\
\hline 1 (Setembro) & 3,16 & 337,96 & $1.267,36$ & $2.816,36$ \\
\hline 2 (Outubro) & 2,78 & 333,33 & $1.250,00$ & $2.777,78$ \\
\hline 3 (Novembro) & 2,78 & 333,33 & $1.250,00$ & $2.777,78$ \\
\hline 4 (Dezembro) & 2,78 & 333,33 & $1.250,00$ & $2.777,78$ \\
\hline 5 (Janeiro) & 2,78 & 333,33 & $1.250,00$ & $2.777,78$ \\
\hline 6 (Fevereiro) & 2,59 & 311,11 & $1.166,67$ & $2.592,59$ \\
\hline 7 (Março) & 2,78 & 333,33 & $1.250,00$ & $2.777,78$ \\
\hline 8 (Abril) & 2,78 & 333,33 & $1.250,00$ & $2.777,78$ \\
\hline
\end{tabular}

De acordo com Ituassú; Spera (2018) para o enchimento de viveiros pequenos, de até $1.500 \mathrm{~m}^{2}(0,15 \mathrm{ha})$, cerca de 8 dias é um período razoável. Para viveiros maiores esse prazo pode ser consideravelmente maior, sendo que são necessários 60 dias para encher 100 hectares de área alagada. Os prazos para enchimento de viveiros podem, entretanto, ser variáveis uma vez que estes devem ser cheios o mais rápido possível, para que a criação de peixes possa ser iniciada o quanto antes. Além disto, a demora em encher viveiros pode fazer que o fundo do viveiro fique demasiadamente ressecado, levando ao aparecimento de rachaduras que podem resultar em processos de infiltração.

Entretanto, estas vazões são variáveis, ou seja, variam conforme a estação do ano. Dessa maneira, é prudente que as determinações das vazões sejam feitas ao longo de um ciclo hidrológico, a fim de que se conheçam as vazões máximas e mínimas do corpo hídrico e da bacia que se pretende usar como fonte de suprimento de água para o cultivo (Ituassú \& Spera, 2018).

A portaria SDS no 036, de 29 de julho 2008 estabelece o limite máximo individual para usos consuntivos a serem outorgados na porção da bacia hidrográfica limitada por cada seção fluvial considerada seja fixado em $20 \%$ da vazão outorgável (Santa Catarina, 2006). Deste modo, os limites outorgáveis para a aquicultura operam entre as faixas de $20 \%$ para mais sendo o limite máximo, e 20\% para menos sendo o limite mínimo outorgável. A Tabela 12 demonstra os limites mínimos de consistência para sistema de cultivo semi-intensivo, e a Tabela 13, abaixo, determina os limites máximos o mesmo sistema. 
Tabela 12 - Limite mínimo individual (L/s) em sistema semi-intensivo.

\begin{tabular}{c|c|c|c|c}
\hline $\begin{array}{c}\text { Área }\left(\mathbf{m}^{2}\right) \\
\text { Mês }\end{array}$ & $\mathbf{1 0 0}$ & $\mathbf{1 . 0 0 0}$ & $\mathbf{3 . 0 0 0}$ & $\mathbf{1 0 . 0 0 0}$ \\
\hline 1 (Setembro) & 0,092 & 1,08 & 16,32 & 36,63 \\
\hline 2 (Outubro) & 0,058 & 0,67 & 2,43 & 5,77 \\
\hline 3 (Novembro) & 0,058 & 0,67 & 2,43 & 5,77 \\
\hline 4 (Dezembro) & 0,058 & 0,67 & 2,43 & 5,77 \\
\hline 5 (Janeiro) & 0,058 & 0,67 & 2,43 & 5,77 \\
\hline 6 (Fevereiro) & 0,054 & 0,62 & 2,27 & 5,38 \\
\hline 7 (Março) & 0,058 & 0,67 & 2,43 & 5,77 \\
\hline 8 (Abril) & 0,058 & 0,67 & 2,43 & 5,77 \\
\hline
\end{tabular}

Tabela 13 - Limite máximo individual (L/s) em sistema semi-intensivo.

\begin{tabular}{c|c|c|c|c}
\hline $\begin{array}{c}\text { Área }\left(\mathbf{m}^{2}\right) \\
\text { Mês }\end{array}$ & $\mathbf{1 0 0}$ & $\mathbf{1 . 0 0 0}$ & $\mathbf{3 . 0 0 0}$ & $\mathbf{1 0 . 0 0 0}$ \\
\hline 1 (Setembro) & 0,138 & 1,62 & 24,48 & 54,95 \\
\hline 2 (Outubro) & 0,086 & 1,00 & 3,64 & 8,65 \\
\hline 3 (Novembro) & 0,086 & 1,00 & 3,64 & 8,65 \\
\hline 4 (Dezembro) & 0,086 & 1,00 & 3,64 & 8,65 \\
\hline 5 (Janeiro) & 0,086 & 1,00 & 3,64 & 8,65 \\
\hline 6 (Fevereiro) & 0,080 & 0,93 & 3,40 & 8,07 \\
\hline 7 (Março) & 0,086 & 1,00 & 3,64 & 8,65 \\
\hline 8 (Abril) & 0,086 & 1,00 & 3,64 & 8,65 \\
\hline
\end{tabular}

Do mesmo modo, a Tabela 14 determina os valores mínimos individual para sistema intensivo de produção, enquanto a Tabela 15, abaixo, demonstra os limites máximos para o mesmo sistema.

Tabela 14 - Limite mínimo individual (L/s) em sistema intensivo.

\begin{tabular}{c|c|c|c|c}
\hline $\begin{array}{c}\text { Área }\left(\mathbf{m}^{2}\right) \\
\text { Mês }\end{array}$ & $\mathbf{1 0 0}$ & $\mathbf{1 . 0 0 0}$ & $\mathbf{3 . 0 0 0}$ & $\mathbf{1 0 . 0 0 0}$ \\
\hline 1 (Setembro) & 2,53 & 270,37 & $1.013,89$ & $2.253,09$ \\
\hline 2 (Outubro) & 2,22 & 266,66 & $1.000,00$ & $2.222,22$ \\
\hline 3 (Novembro) & 2,22 & 266,66 & $1.000,00$ & $2.222,22$ \\
\hline 4 (Dezembro) & 2,22 & 266,66 & $1.000,00$ & $2.222,22$ \\
\hline 5 (Janeiro) & 2,22 & 266,66 & $1.000,00$ & $2.222,22$ \\
\hline 6 (Fevereiro) & 2,07 & 248,89 & 933,34 & $2.074,07$ \\
\hline 7 (Março) & 2,22 & 266,66 & $1.000,00$ & $2.222,22$ \\
\hline 8 (Abril) & 2,22 & 266,66 & $1.000,00$ & $2.222,22$ \\
\hline
\end{tabular}

Tabela 15 - Limite máximo individual (L/s) em sistema intensivo.

\begin{tabular}{c|c|c|c|c}
\hline $\begin{array}{c}\text { Área }\left(\mathbf{m}^{2}\right) \\
\text { Mês }\end{array}$ & $\mathbf{1 0 0}$ & $\mathbf{1 . 0 0 0}$ & $\mathbf{3 . 0 0 0}$ & $\mathbf{1 0 . 0 0 0}$ \\
\hline 1 (Setembro) & 3,79 & 405,55 & $1.520,83$ & $3.379,63$ \\
\hline 2 (Outubro) & 3,34 & 400,00 & $1.500,00$ & $3.333,34$ \\
\hline 3 (Novembro) & 3,34 & 400,00 & $1.500,00$ & $3.333,34$ \\
\hline 4 (Dezembro) & 3,34 & 400,00 & $1.500,00$ & $3.333,34$ \\
\hline 5 (Janeiro) & 3,34 & 400,00 & $1.500,00$ & $3.333,34$ \\
\hline 6 (Fevereiro) & 3,11 & 373,33 & $1.400,00$ & $3.111,11$ \\
\hline 7 (Março) & 3,34 & 400,00 & $1.500,00$ & $3.333,34$ \\
\hline 8 (Abril) & 3,34 & 400,00 & $1.500,00$ & $3.333,34$ \\
\hline
\end{tabular}

As porcentagens estabelecidas pelas normas estaduais em relação às vazões de restrição visam proteger o corpo hídrico, adotando um padrão conservador, já que o critério quase sempre exercido é de um valor mínimo constante. Quando a tomada de decisão para esse parâmetro é feita de forma 
genérica, sem estudos específicos ou justificativas de definições dos padrões adotados e dos limites para as vazões outorgáveis, tanto dificulta a gestão, como pode gerar conflitos dentre os múltiplos usuários da água (Souza, 2020).

A responsabilidade da alocação da água é individualizada, ou seja, cada usuário relacionado é individualmente responsável pelo uso que lhe foi outorgado (Agência Nacional de Águas, 2014). Considerando as Tabelas 12 e 14 de limite mínimo individual de cada sistema, confere o menor valor de vazão da água que deve ser considerado para uma produção. Os valores das Tabelas 13 e 15 são os valores máximos necessários para o abastecimento da produção. Ou seja, as análises de outorgas devem ser praticadas dentro dessa faixa de valores, atribuídos como parâmetros.

A Resolução ANA no 707/2004 (Brasil. Agência Nacional de Águas, 2004) ressalta que o uso racional da água é provido da eficiência, caracterizada pelo proveito da água em níveis tecnicamente reconhecidos como coerentes, considerando o contexto da finalidade a que se destina, com observância do enquadramento do corpo hídrico e os aspectos tecnológicos, econômicos e sociais.

Questões científicas e de engenharia podem ser remodeladas de acordo com a problemática analisada e tomada de decisão (Tzeng \& Huang, 2011). Se numa análise for verificado que a vazão de uma propriedade é maior ou menor que os valores estipulados como máximos e mínimos, pode ser considerado um super ou sub dimensionamento da produção, em vista disso, cabe o analista recusar pedido, já que não se qualifica dentro dos parâmetros firmados para a atividade.

A demanda e a disponibilidade de água são dois componentes importantes que dominam intensamente os padrões de alocação para terras agrícolas e que conduzem ao desenvolvimento sustentável (Li et al, 2021). A outorga de direito de uso da água é um dos instrumentos mais importantes na gestão dos recursos hídricos, os critérios e parâmetros técnicos das análises precisam de melhorias efetivas que contemplem a atividade. Para que haja um desenvolvimento econômico e sustentável, a regularização dos empreendimentos é um fator imprescindível na determinação de vazões outorgáveis (Parcio \& Caramello, 2021).

Para Mesquita (2018), as crises hídricas em bacias não decorrem apenas da redução de precipitações que estão abaixo das médias históricas, e sim também, da ocupação desordenada do solo, do descumprimento da legislação ambiental e do planejamento precário no que se refere aos aspectos ecológicos, sociais e de interesse coletivo.

Aprimorar a estruturas de modelagem participativa pode corresponder uma abordagem promissora para compreender e promover o desenvolvimento e aplicação dos melhores modelos ambientais disponíveis. Estas representações podem ser de grande ajuda nas tomadas de decisões e da gestão ambiental, elucidando o comportamento das demandas e disponibilidades a partir de prognósticos, estimando-se a partir das análises políticas, planos ou intenções setoriais de uso, controle e proteção dos recursos hídricos (Özkundakci et al., 2018).

Com o sistema de licenciamento torna as autoridades públicas responsáveis pelos resultados da outorga para aquicultura, sendo fundamental a organização das metas, critérios e processos administrativos, para alcançar eficiência e legitimidade (Hersoug et al., 2021).

\section{Outorga de direito de uso da água em Santa Catarina}

A aquicultura no estado de Santa Catarina representa uma importante atividade de geração de renda e emprego para a população rural, podendo ser classificada com de baixo impacto ambiental e que gera retorno econômico e social (Giehl et al., 2020). Sabendo que cada vez mais o uso dos recursos hídricos será destinado para a produção de pescados, existe a necessidade de orientar o uso do território aquático planejando a manutenção, sustentabilidade e incremento da produção, sem negligenciar a importância da preservação do meio ambiente. Assim existe uma necessidade eminente de se identificar através de modelagens preditivas a capacidade de suporte da produção aquícola, com intuito de evitar a eutrofização dos recursos hídricos, ordenar a quantidade de produtores que uma bacia comporta sem prejudicar a biota aquática natural dos rios.

De acordo com a Agência Nacional de Águas (2013), as vazões dispensadas de outorga são as captações menores que $1 \mathrm{~m}^{3} / \mathrm{d}$. A Tabela 11 e 12 demonstram que para o abastecimento dos viveiros para aquicultura, por menores que estes sejam, as vazões de captação são bem maiores que $1 \mathrm{~m}^{3} / \mathrm{d}$ (ou 0,012 L/s), deste modo, é improvável que os empreendimentos aquícolas se enquadrem como uso com vazão insignificantes e dispensados da outorga.

Segundo a instrução normativa no 6 de 19/05/2011 (Brasil, 2011), a inscrição de pessoa física ou jurídica no Registro Geral da Atividade Pesqueira (RGP), na categoria de aquicultor, estabelece-se de duas fases de caráter complementar, sendo o Registro de Aquicultor a primeira fase e a Licença de Aquicultor a 
fase conclusiva do processo, de acordo com artigo $2^{\circ}$. Para Andrade (2020), a região com maior número de cadastros no Brasil é a região Sul, com 8.731 aquicultores, porém com apenas 95 licenças, sendo a região com o menor número. Essa desconformidade entre aquicultores registrados e licenciados na região Sul pode estar associada ao fato de que os estados dispensam a licença até determinado tamanho de área alagada e por apresentarem um processo simplificado de licenciamento.

Entre os entraves que limitam o crescimento da atividade de aquicultura tem sido destacada a falta de licenciamento ambiental das propriedades, o que dificulta o acesso do produtor a políticas públicas de financiamento, impossibilitando investimentos nas operações que tem alto valor de custeio. É necessário adotar medidas que auxiliem a diminuição da degradação e manter a qualidade dos recursos provenientes das bacias hidrográficas, tal como o incentivo a à implantação de projetos de compensação financeira para usuários que adotarem práticas de conservação de água e solo, a utilização de tecnologias que poupem água, a regularização dos usuários com a inserção dos critérios ambientais, sociais e de uso e ocupação do solo na concessão das outorgas, principalmente na criação de artifícios comunicação entre a sociedade civil e a esfera pública (Mesquita, 2018; Loureiro et al., 2018; Trindade Junior, 2021).

As principais dificuldades relativas as implementações da outorga no estado de Santa Catarina envolvem tanto questões técnicas, administrativas e de disponibilidade de recursos hídricos. As questões técnicas implicam a definição clara de critérios e normativas referentes a implantação da outorga, tais como vazão de referência, mitigação de conflitos, revisão e melhorias nas bases de referência hidrológica que possam auxiliar e dar maior segurança a tomada de decisão. As questões administrativas estão relacionadas a relação número de requerimentos de outorga e de técnicos envolvidos na análise. Cabe salientar que grande maioria dos processos protocolados apresentam documentação faltante ou equivocada, demandando frequentemente reanalises, tendo em média três análises técnicas por processo. Dentre as algumas soluções já identificadas destaca-se o treinamento dos profissionais da equipe interna comprometidos com as analises, quanto das equipes técnicas externas envolvidas nos requerimentos das outorgas. Bem como, a padronização dos procedimentos de avaliação, necessitando a ampliação e valorização da equipe efetiva de análise e fiscalização. Contudo, para tudo isso que ocorra, envolve maior comprometimento do Estado.

Está em andamento a implantação do "Sistema Estadual de Outorga" que irá contribuir para dar celeridade aos procedimentos relativos à análise, principalmente exigindo que os requerentes façam as suas solicitações somente após a apresentação da documentação mínima necessária.

É pretendido que para os próximos 5 anos os procedimentos de análise de outorga ocorram de forma célere, com o processo ocorrendo, em média, de até 3 meses, (comunicação pessoal) ${ }^{1}$. Almeja-se que estes procedimentos envolvam muito mais que a mera análise de pedidos, e sim que, conjuntamente, ocorra a verificação de ampliação de reservas e fontes alternativas, desenvolvimento do monitoramento qualitativo e quantitativo, como também, a fiscalização dos usos dos recursos hídricos.

\section{CONCLUSÕES}

A premissa que envolve a outorga por si só já representa um grande desafio que é garantir água em quantidade e qualidade para a atual e futuras gerações. Neste estudo foi apresentado um modelo de cálculo para a avaliação da demanda hídrica das propriedades aquícolas continentais nas análises da outorga de direito de uso dos recursos hídricos, proporcionando maior segurança no uso das águas ao levar em consideração os sistemas de produção aquícola para vários tamanhos de viveiros e sistemas de cultivos, bem como aspectos fundamentais como tipo de solo, peculiaridades meteorológicas e hídricas dos principais sistemas e espécies de cultivo implantados em Santa Catarina

Foi apresentada uma sugestão de metodologia a partir de adaptações de cálculos para dimensionamento hídrico longo de um ciclo de cultivo aquícola, considerando as variáveis sazonais que atuam sobre a quantidade de água necessária.

Além disso, este estudo corrobora que a aquicultura em Santa Catarina é uma atividade passível de outorga devido a demanda hídrica ser maior que $1 \mathrm{~m}^{3} /$ dia, por menores que sejam as lâminas de água. A dispensa desta pode acarretar em inconsistência na gestão dos recursos ambientais, com possibilidade de agravamento de crises hídricas e conflitos entre os usos múltiplos.

Desta maneira, a modelagem ambiental visa contribuir positivamente ao processo decisório de gestões, auxiliando os analistas de outorga de direito de recursos hídricos, em simultâneo com a avaliação do uso racional da água. Salienta-se que deve ser levado em conta as especificidades de cada bacia hidrográfica em que está inserido o empreendimento a ser outorgado, como os aspectos meteorológicos, de solo e as técnicas de cultivo usuais interatuam com a demanda hídrica. Neste trabalho foi apresentando um modelo preliminar 
e generalizado para o estado, sendo possível que o procedimento seja aproveitado para minuciar as localidades em Santa Catarina, bem como, expandir para as demais unidades da federação.

Santa Catarina está desenvolvendo estratégias de melhorias do sistema de informação para outorga, promovendo agilidade ao progresso da gestão para aquicultura. Essas melhorias proporcionam desenvolvimento ao setor, uma vez que o instrumento de outorga é fundamental para que o usuário tenha respaldo jurídico e a garantia da demanda requisitada, bem como para que os gestores tenham concepção da veracidade socioambiental. Não obstante, a posterior averiguação é mensurar se as demandas hídricas necessárias para abastecimento de atividade condizem com a disponibilidade de seus corpos hídricos juntamente com os usos múltiplos neles inseridos.

\section{REFERÊNCIAS}

Agência Nacional de Águas - ANA. (2013). Atlas Brasil: manual de procedimentos técnicos e administrativos de outorga de direito de uso de recursos hídricos. Brasília.

Agência Nacional de Águas - ANA. (2014). Manual de procedimentos técnicos e administrativos (Vol. 2013, 240 p.). Brasília.

Andrade, A. S. (2020). Brazilian aquaculture: the view of the Ministry of Agriculture, Livestock and Supply based on the general registration system for fisheries and aquaculture. Research Social Development, 9(10), e2759108398. http://dx.doi.org/10.33448/rsd-v9i10.8398

Avnimelech, Y., Verdegem, M., Kurup, M., \& Keshavanath, P. (2008). Sustainable land-based aquaculture: rational utilization of water, land and feed resources. Mediterranean Aquaculture Journal, 1(1), 45-54.

Bertol, I., \& Almeida, J. A. (2000). Tolerância de perda de solo por erosão para os principais solos do Estado de Santa Catarina. Revista Brasileira de Ciência do Solo, 24(3), 657-668.

Brasil. (2006, 30 de outubro). Portaria SDS n. 035, de 30 de outubro de 2006. Dispõe sobre procedimentos de natureza técnica e administrativa a serem observados no exame de pedidos de outorga e dá outras providências. Diário Oficial [da] República Federativa do Brasil, Brasília.

Brasil. (2009, 30 de junho). Leis, Decretos etc. Resolução Conama no 413, de 26 de junho de 2009. Dispõe sobre o licenciamento ambiental da aquicultura, e dá outras providências. Diário Oficial [da] República Federativa do Brasil, Brasília.

Brasil. (2011). Instrução normativa MPA n. 6, de 20 de maio de 2011. Dispõe sobre o Registro e a Licença de Aquicultor, para o Registro Geral da Atividade Pesqueira - RGP. Diário Oficial [da] República Federativa do Brasil, Brasília.

Brasil. Agência Nacional de Águas - ANA. (2004). Resolução ANA no 707, de 21 de dezembro de 2004. Diário Oficial [da] República Federativa do Brasil, Brasília.

Brigolin, D., Lourguioui, H., Taji, M. A., Venier, C., Mangin, A., \& Pastres, R. (2015). Space allocation for coastal aquaculture in North Africa: data constraints, industry requirements and conservation issues. Ocean and Coastal Management, 116, 89-97.

Casaca, J. M. (2008). Policultivo de peixes integrados à produção vegetal: avaliação econômica e socioambiental. Universidade Estadual Paulista. Jaboticabal, p. 162.

Casaca, J. M. (2020). Manual do licenciamento ambiental da piscicultura de águas continentais de Santa Catarina: Autorização ambiental (AuA) (Documentos, No. 325).

Casarin, F., \& Santos, M. (2018). Água: o ouro azul: usos e abusos dos recursos hídricos. Editora Garamond.

Conejo, G. L. (1993). A outorga de usos da água como instrumento de gerenciamento dos recursos hídricos. Revista de Administração Pública, 27(2), 28-62.

Daga, V. S., Skóra, F., Padial, A. A., Abilhoa, V., Gubiani, E. A., \& Vitule, J. R. S. (2015). Dinâmica de homogeneização das assembléias de peixes em reservatórios Neotropicais: comparando os papéis de espécies introduzidas e seus vetores. Hidrobiologia, 746(1), 327-347.

Deus, F. O., \& Latuf, M. O. (2019). Outorga e suas implicações na piscicultura no entorno do reservatório de Furnas. Caderno de Geografia, 29(2), 143-157.

Dotta, G., \& Piazza, R. S. (2018). Manejo e sanidade no cultivo. Curitiba.

Empresa de Pesquisa Agropecuária e Extensão Rural de Santa Catarina - EPAGRI. Centro de Socioeconomia e Planejamento Agrícola - CEPA. (2019a). Sintese anual da Agricultura de Santa Catarina 2016-2017. Recuperado em 13 de novembro de 2020, de https://publicacoes.epagri.sc.gov.br/SAA/article/view/521 
Empresa de Pesquisa Agropecuária e Extensão Rural de Santa Catarina - EPAGRI. Centro de Desenvolvimento em Aquicultura e Pesca - CEDAP. (2019b). Recuperado em 13 de novembro de 2020, de https://cedap.epagri.sc.gov.br/index.php/estudos/\# estatisticas

Fonseca, S. B., Mendes, P. P., Albertim, C. J. L., Bittencourt, C. F., \& Silva, J. H. V. (2009). Cultivo do camarão marinho em água doce em diferentes densidades de estocagem. Pesquisa Agropecuária Brasileira, 44(10), 1352-1358.

Giehl, A. L., Novaes, A. L. T., Feliciano, A. M., Silva, F. M., Alves, J. R., Toresan, L., Souza, R. V., Goulart Junior, R., \& Marcondes, T. (2020). Números da agropecuária catarinense - 2020 (264p.). Florianópolis: Epagri.

Gonçalves, F. N. (2017). Índices de precipitação para o Estado de Santa Catarina (202 p.).

Gotado, R., Piazza, G. A., Torres, E., Severo, D. L., \& Kaufman, V. (2018). Distribuição espacial e temporal das chuvas no estado de Santa Catarina. Geosul, 33(67), 253-276.

Gutiérrez-Estrada, J. C., Pulido-Calvo, I., de la Rosa, I., \& Marchini, B. (2012). Modeling inflow rates for the water exchange management in semi-intensive aquaculture ponds. Aquacultural Engineering, 48, 19-30.

Hersoug, B., Olsen, M. S., Gauteplass, A. A., Osmundsen, T. C., \& Asche, F. (2021). Serving the industry or undermining the regulatory system? The use of special purpose licenses in Norwegian salmon aquaculture. Aquaculture, 543, 736918.

Ituassú, D. R., \& Spera, S. T. (2018). Abordagem prática do dimensionamento da demanda hídrica em projetos de piscicultura (Circular Técnica). Embrapa Agrossilvipastoril.

Kubitza, F. (2009). Manejo na produção de peixes. Panorama da Aquicultura, 19(111), 14-27.

Li, M., Sun, H., Liu, D., Singh, V. P., \& Fu, Q. (2021). Multi-scale modeling for irrigation water and cropland resources allocation considering uncertainties in water supply and demand. Agricultural Water Management, 246, 106687.

Lopes, A. C., Rupp, R. F., \& Ghisi, E. (2016). Assessment of the potential for potable water savings by using rainwater in houses in southern Brazil. Water Science and Technology: Water Supply, 16(2), 533-541.

Lorensi, R. P., Zardo, K., Mattar, D. M. P., \& Nishijima, T. (2010). A utilização dos recursos hídricos no sistema de irrigação por superfície (inundação) na cultura do arroz mediante as normatizações. Ambiência, 6(2), 355-364.

Loureiro, B. R., Routledge, E. A. B., \& Nuñer, A. P. O. (2018). Subsídios para a regularização ambiental da aquicultura brasileira. In Engenharia de aquicultura no Brasil: pesquisas, tendências e atualidades (p. 52).

Mesquita, L. F. G. (2018). River basin committees and integrated management in the brazilian national water resources policy. Desenvolvimento e Meio Ambiente, 45, 56-80.

Montaño, M., \& Souza, M. P. (2016). Integração entre planejamento do uso do solo e de recursos hídricos: a disponibilidade hídrica como critério para a localização de empreendimentos. Engenharia Sanitaria e Ambiental, 21(3), 489-495.

Oliveira, L. F. C., \& Fioreze, A. P. (2011). Estimativas de vazões mínimas mediante dados pluviométricos na Bacia Hidrográfica do Ribeirão Santa Bárbara, Goiás. Revista Brasileira de Engenharia Agrícola e Ambiental, 15(1), 9-15.

Oliveira, M. A. (2005). Engenharia para aquicultura (241 p.). Fortaleza: Ed. do Autor.

Ono, E. A., Campos, J. L., \& Kubitza, F. (2002). Construção de viveiros e de estruturas hidráulicas para o cultivo de peixes. Parte 3: as estruturas hidráulicas. Panorama da Aquicultura, 12(74), 15-29.

Özkundakci, D., Wallace, P., Jones, H. F. E., Hunt, S., \& Giles, H. (2018). Building a reliable evidence base: legal challenges in environmental decision-making call for a more rigorous adoption of best practices in environmental modelling. Environmental Science \& Policy, 88, 52-62.

Panachuki, E., Bertol, I., Alves Sobrinho, T., Oliveira, P. T. S., \& Rodrigues, D. B. B. (2011). Perdas de solo e de água e infiltração de água em latossolo vermelho sob sistemas de manejo. Revista Brasileira de Ciência do Solo, 35(5), 1777-1786.

Parcio, J. A., \& Caramello, N. (2021). Proteção jurídico-normativa da água. Nature and Conservation, 14(1), 169-180.

Paz, R. J., Escarião, R. D., Lima, A. P., \& Tavares, P. T. (2013). Gestão Ambiental Licenciamento ambiental de empreendimentos aquícolas. In Anais do Congresso Brasileiro de Gestão Ambiental e Sustentabilidade (Vol. 1, pp. 37-42).

PeixeBR. (2020). Anuário PeixeBr da Piscicultura (Vol. 28).

Peres, R. B., \& Silva, R. S. (2013). Interfaces da gestão ambiental urbana e gestão regional: análise da relação entre Planos Diretores Municipais e Planos de Bacia Hidrográfica. urbe. Revista Brasileira de Gestão Urbana, 5(480), 13.

Poli, C. A. (2003). Aquicultura: experiências brasileiras. Multitarefa. 
Porto, M. F. A., \& Porto, R. L. L. (2008). Gestão de bacias hidrográficas. Estudos Avançados, 22(63), 43-60.

Queiroz, J. F., \& Silveira, M. P. (2006). Recomendações práticas para melhorar a qualidade da água e dos efluentes dos viveiros de aqüicultura (Circular Técnica, No. 12, pp. 1-14). Embrapa Meio Ambiente.

Ramos, M. C. A. (2016). Critérios de valoração da água com base na sazonalidade das vazões e na efetiva demanda hídrica das culturas (Dissertação de mestrado). Universidade Federal de Viçosa, Viçosa.

Ritter, F., Pandolfo, A., Barcellos, L. J. G., Mezzalira Quevedo, R., Santos Ritter, V. R., Pimentel Gomes, A., \& Marcondes Pandolfo, L. (2014). Análise da viabilidade econômica do policultivo de Carpas, Jundiás e Tilápias-do-Nilo como uma alternativa de modelo de cultivo de peixes para pequenas propriedades. Brazilian Journal of Aquatic Science and Technology, 17(2), 27.

Rocha, J. L. O. (2020). Caracterização do solo de viveiros de cultivo intensivo e extensivo de Litopenaeus vannamei (BOONE, 1931): um estudo de caso no nordeste do Brasil (Dissertação de mestrado). Universidade Federal de Santa Catarina, Florianópolis.

Rodell, M., Famiglietti, J. S., Wiese, D. N., Reager, J. T., Beaudoing, H. K., Landerer, F. W., \& Lo, M.-H. (2018). Emerging trends in global freshwater availability. Nature, 557(7707), 651-659.

Rodrigues, L., Cavalcanti, I., Capanema, L., Morch, R., Magalhães, G., Lima, J., Burns, V. A. C., Alves Júnior, A. J., \& Mungioli, R. P. (2012). Panorama da aquicultura no Brasil: desafios e oportunidades Panorama da aquicultura no Brasil: desafios e oportunidades. Agroindústria.

Santa Catarina. Secretária de Estado do Desenvolvimento Econômico e Sustentável - SDS. (2006). Panorama dos Recursos Hídricos no Estado de Santa Catarina.

Santa Catarina. Secretária de Estado do Desenvolvimento Econômico e Sustentável - SDS. (2018). Recursos hídricos de Santa Catarina (p. 31). Rede Hidrográfica Catarinense.

Silva, J. B. W. (1988). Piscicultura intensiva e semi-intensiva: manual sobre manejos de reservatórios para produção de peixes (p. 8.1). Rome: FAO .

Simões, J. A. B. (2016). Avaliação do impacto ambiental de duas truticulturas em raceway sobre seus córregos receptores (Dissertação de mestrado). Universidade Federal de Minas Gerais, Belo Horizonte.

Sistema de Informações e Recursos Hídricos do Estado de Santa Catarina - SIRHESC. (2019). Bibliotecas.

Souza, T. P. (2020). Análise de métodos de outorga considerando os aspectos qualitativos e quantitativos (Dissertação de mestrado). Universidade Federal de Alagoas, Maceió.

Steinmetz, S., \& Braga, H. J. (2001). Zoneamento de arroz irrigado por épocas de semeadura nos Estados do Rio Grande do Sul e de Santa Catarina. Revista Brasileira de Agrometeorologia, 9(3), 429-438.

Tabata, Y. A., \& Silva Filho, J. M. (2012). Boas práticas na truticultura (p. 68).

Trindade Junior, A. P. (2021). Contextos da política de águas e novas abordagens pela perspectiva das reformas administrativas no Brasil. Administração Pública e Gestão Social, 13(1).

Tzeng, G. H., \& Huang, J. J. (2011). Multiple attribute decision making: methods and applications. CRC Press.

Walber, B. (2007). Manual do piscicultor (61 p.). Ed. UNIJUI.

Zaniboni-Filho, E., Pedron, J. S., \& Ribolli, J. (2018). Oportunidades e desafios para a aquicultura em reservatórios brasileiros: uma revisão. Acta Limnologica Brasiliensia, 30.

\section{Contribuições dos autores:}

Izabella Alves Cordeiro de Farias: execução do projeto e escrita do trabalho.

Leonardo Schorcht Bracony Porto Ferreira: idealização do projeto e correção do trabalho.

Rodrigo Nascimento e Silva: produção dos mapas e correção do trabalho.

Celso Lopes de Albuquerque Junior: contribuição das discussões e correção do trabalho.

Katt Regina Lapa: orientação e correção do trabalho. 